\title{
A pedagogia guarani nas percepções dos professores guarani e kaiowá do Mato Grosso do Sul
}

\section{Guarani pedagogy in the perceptions of teachers Guarani and Kaiowá from Mato Grosso do Sul}

\author{
Carlos Magno Naglis VIEIRA ${ }^{1}$
}

Aurieler Jaime de ABREU²

\begin{abstract}
Resumo
Utilizando como eixo teórico autores indígenas e não indígenas que dialogam com os estudos da cultura e da pedagogia guarani, a pesquisa apresenta as percepçóes dos professores guarani e kaiowá do Mato Grosso do Sul sobre a pedagogia guarani. Tendo como objeto de análise os relatórios da Ação Saberes Indígenas na Escola/ MEC/SECADI, o trabalho demostrou que a pedagogia guarani é transmitida de maneira oral, possuindo elementos e modos próprios, apresentando reflexóes sobre os conhecimentos tradicionais, autonomia e modo de ser que se fazem presentes entre os membros da comunidade e que circulam com as crianças na escola.
\end{abstract}

Palavras-chave: Pedagogia Guarani, Professores Guarani e Kaiowá, Mato Grosso do Sul, Saberes Indígenas na Escola.
Abstract

Using as a theoretical axis, indigenous and non-indigenous altos who dialogue with the studies of Guarani culture and pedagogy, the research presents the perceptions of the Guarani and Kaiowá teachers of Mato Grosso do Sul, on Guarani pedagogy. Having as analysis, the reports of the Action Indigenous Knowledge in School/MEC/SECADI, the work demonstrated that the Guarani pedagogy is transmitted orally, possessing elements and own ways, presenting reflections on the traditional knowledge, autonomy and the way of being, is present among members of the community and circulates with children in school.

Keywords: Guarani Pedagogy, Guarani and Kaiowá Teachers, Mato Grosso do Sul, Indigenous Knowledge at School.

1 Professor e pesquisador do Programa de Pós-Graduaçáo em Educação da Universidade Católica Dom Bosco/Campo Grande. http://orcid.org/0000-0003-4004-4836. Lattes: http://lattes.cnpq. br/0757780259670322. E-mail: vieira@ucdb.br

2 Mestre em Educação pela Universidade Católica Dom Bosco/Campo Grande. https://orcid.org/00000001-6679-2969. Lattes: http://buscatextual.cnpq.br/buscatextual/visualizacv.do?id=K8114563E5. E-mail: auri0jaime@gmail.com 
Nos últimos anos, muitas pesquisas foram desenvolvidas com e sobre populações indígenas. Em algumas produções, identificamos os cuidados dos pesquisadores em anunciar os inúmeros desafios de pesquisar com os povos indígenas, principalmente no que se refere aos caminhos, à atenção, à sensibilidade, aos ruídos e à vigilância teórica e metodológica. No entanto, é importante evidenciar que nem todos os pesquisadores não indígenas, que se propóem a esse trabalho, necessariamente vão senti-los da mesma maneira.

A partir da nossa experiência de pesquisa com o povo guarani e kaiowá do Mato Grosso do Sul, procuramos, nesse texto, evidenciar uma tarefa desafiadora que é apresentar o indígena, suas percepçóes, sem as teorias ocidentais e seus pré-julgamentos. Por meio da análise de relatórios de formação produzidos pelos professores guarani e kaiowá de Mato Grosso do Sul sobre a Ação Saberes Indígenas na Escola/MEC/SECADI (ASIE), tentaremos realizar o exercício de apresentar o outro. Colocamos como exercício porque entendemos que toda escrita tem uma marca, independente de quem a escreve, pois a escrita não é neutra: está repleta de significados culturais, identitários e de reconhecimento. Sendo assim, escrevemos conforme nossas percepçóes de mundo, de acordo com a formação de nosso Eu e de nosso olhar em relação ao Outro.

Para uma discussão mais próxima da temática da pesquisa, buscamos inspiração de autores indígenas e não indígenas. Seus escritos, além de colaborarem com as nossas análises da pesquisa, nos auxiliam e nos movem a percorrer caminhos diferenciados, contribuem para uma aproximação com o outro, despertam a sensibilidade e o respeito, além de proporcionar elementos para nossa escrita sobre comportamentos e atitudes. Entre os pesquisadores não indígenas, destacamos neste artigo os trabalhos de Arroyo (2012), Brand (1993, 1997, 2004), Bergamaschi (2005) e Nascimento e Scaramuzza (2018). Além destes, muitos outros nos inspiram nesta produção.

Amparado em produçôes realizadas pelos intelectuais guarani e kaiowá do Mato Grosso do Sul, o artigo manifesta que as produçóes indígenas, além de trazerem o protagonismo dos índios, mostram modos outros de se fazer pesquisa, narrar histórias e apresentar saberes e conhecimentos próprios (AQUINO, 2012; LESCANO, 2016; BENITES, 2014; MACHADO, 2016). Por meio desses trabalhos acadêmicos dos guarani e kaiowá, aprendemos a saber ouvir e a ouvir com atenção, com respeito e com sabedoria. Entendemos que o ato de utilizar a audição não é uma capacidade física, mas um elemento que vem da alma, do sensível, da sabedoria que não está visível (LESCANO, 2016). É um elemento que não se ensina por meio de receitas, mas que se aprende quando estamos abertos. Utilizando-se de outras palavras, não se trata de sentar em silêncio diante de seus pares, mas, sim, de sentar com respeito e de estar aberto a receber aquilo que querem entregar por meio de conhecimento (BENITES, 2014; LESCANO, 2016). 
Os estudos de Walsh (2009; 2016), Quijano (2005) e Lander (2005), com produçóes norteadas pela teoria da pós-colonialidade, todos pertencentes ao grupo Modernidade e Colonialidade ${ }^{3}$, contribuíram com provocaçóes, construções e inquietaçóes críticas quanto à nossa compreensão de pensar e fazer pesquisa, além de auxiliarem na maneira de escrever os resultados neste trabalho.

A partir desses primeiros escritos, mediados pelos autores mencionados, é que buscamos dar sintonia ao texto. $\mathrm{O}$ artigo, resulta de uma pesquisa realizada junto ao Programa de Pós-Graduação em Educação da Universidade Católica Dom Bosco (UCDB), desenvolvido pelo Grupo de Pesquisa Educação Intercultural e Povos Tradicionais/CNPq. Buscamos apresentar as percepçóes dos professores/as guarani e kaiowá acerca da pedagogia guarani a partir dos relatórios produzidos após as formações da Ação Saberes Indígenas na Escola/MEC/SECADI (ASIE) em três terras indígenas de Mato Grosso do Sul, sendo elas: Guaimbé (município de Laguna Caarapã/MS), Rancho Jacaré (município de Laguna Caarapã/MS), e Taquapery (município de Coronel Sapucaia/MS).

A Ação Saberes Indígenas na Escola/MEC/SECADI, instituída pela portaria 1.061 de 30 de outubro de 2013, é uma política estabelecida pelo Ministério da Educação/MEC e integrante do Programa Nacional dos Territórios Etnoeducacionais ${ }^{4}$, cujo os objetivos se destinam a:

I - promover a formação continuada de professores da educação escolar indígena, especialmente daqueles que atuam nos anos iniciais da educação básica nas escolas indígenas;

II - oferecer recursos didáticos e pedagógicos que atendam às especificidades da organização comunitária, do multilinguismo e da interculturalidade que fundamentam os projetos educativos nas comunidades indígenas; III - oferecer subsídios à elaboração de currículos, definição de metodologias e processos de avaliação que atendam às especificidades dos processos de letramento, numeramento e conhecimentos dos povos indígenas;

3 O grupo Modernidade/Colonialidade é constituído por inúmeros intelectuais de nacionalidade latinoamericana e americanista. Dentre eles, se destacam o filósofo argentino, Enrique Dussel; o sociólogo peruano, Aníbal Quimano; o semiólogo e teórico cultural argentino, Walter Mignolo, o sociólogo portoriquenho, Ramón Grosfoguel; a linguista norte-americana radicada no Equador, Catherine Walsh; o filósofo porto-riquenho, Nelson Maldonado Torres; o filósofo colombiano, Santiago Castro-Gómez; o sociólogo venezuelano, Edgardo Lander; o antropólogo colombiano, Arturo Escobar; a semióloga argentina Zulma Palermo; o antropólogo venezuelano, Fernando Coronil; e o sociólogo norte-americano, Immanuel Wallerstein.

Decreto 6.861 de 27 de maio de 2009. 
IV - fomentar pesquisas que resultem na elaboração de materiais didáticos e paradidáticos em diversas linguagens, bilíngues e monolíngues, conforme a situação sociolinguística e de acordo com as especificidades da educação escolar indígena (BRASIL, 2013, p. 1-2).

Essa ação surgiu de uma demanda do Programa Nacional dos Territórios Etnoeducacionais, na qual se reafirma o compromisso e o respeito do MEC com a educação escolar indígena, tanto na educação básica quanto no ensino superior. A principal atividade realizada por essa política é a formação continuada de professores indígenas, principalmente aqueles que estão em exercício nos anos iniciais da educação básica de escolas indígenas. É importante ressaltar, ainda com base na portaria 1.061/2013, que a Ação Saberes Indígenas na Escola (ASIE) obedece às diretrizes do Pacto Nacional pela Alfabetização na Idade Certa (PNAIC), podendo utilizar açóes complementares, de acordo com as especificidades da educação escolar indígena (BRASIL, 2013).

Em todo território nacional, a Ação Saberes Indígenas na Escola (ASIE) se divide em oito redes de trabalho e reúne inúmeras instituições de ensino superior público e privado. O Mato Grosso do Sul, espaço de análise neste texto, corresponde a uma dessas redes nacionais. A rede MS, como é conhecida, iniciou suas atividades em 2013 e é composta por 04 universidades: Universidade Federal do Mato Grosso do Sul (UFMS), Universidade Católica Dom Bosco (UCDB), Universidade Estadual de Mato Grosso do Sul (UEMS) e Universidade Federal da Grande Dourados (UFGD), todas coordenadas pela UFMS. No estado, a política de formação continuada de professores indígenas compreende os Territórios Etnoeducacionais Povos do Pantanal e Cone Sul e atende os povos indígenas das etnias guarani e kaiowá, terena, kadiwéu, guató, kiniquinau e ofaié.

\section{Os caminhos metodológicos}

Para a elaboração do trabalho, fez-se necessário algum contorno metodológico, ou seja, além das nossas experiências de pesquisadores, foi preciso realizar uma leitura atenta e vigilante dos documentos da Ação Saberes Indígenas na Escola. A produção dos dados de pesquisa ocorreu a partir da análise dos relatórios elaborados pelos professores guarani e kaiowá após as formaçóes da ASIE de três terras indígenas de Mato Grosso do Sul.

Os relatórios que colaboraram com a pesquisa, ou seja, analisados, são frutos de formaçôes que ocorreram no período de 2017 e 2018, nas escolas guarani e kaiowá, tendo como elemento norteador as práticas pedagógicas voltadas ao conhecimento tradicional e sua relaçâo com as questôes que envolvem o letramento, 
o numeramento, os processos próprios de aprendizagens e a produção de material didático específico e diferenciado. Em sua maioria, os relatórios eram produzidos em forma de memoriais do dia, onde os professores traziam para o papel a discussão da formação atravessada pela sua prática pedagógica. Nos relatórios, as práticas docentes mencionadas estavam amparadas pela pedagogia guarani.

Foram muitos relatórios produzidos pelos docentes guarani e kaiowá das terras indígenas mencionadas acima durante a Ação Saberes Indígena na Escola, porém, para a pesquisa e também para a produção do artigo, utilizamos a análise de somente 14 (quatorze) relatórios dos professores. Alguns relatórios foram produzidos de forma individual, outros coletivamente; sendo assim, ficaria difícil apontar autores/as ao longo do diálogo realizado com as produçôes. Vale mencionar que os professores atuam nas escolas indígenas, ministram suas aulas na educação básica e, em sua maioria, foram aprovados em concurso público específico e com formação diferenciada, seja no magistério indígena ou na Licenciatura Intercultural.

Para melhor compreensão dos relatórios, ao longo do artigo, iremos nomeálos de R-1 a R-14, identificando apenas a terra indígena a que se refere, pois compreendemos que mesmo aqueles assinados individualmente foram gestados através da coletividade dos encontros em que foram produzidos.

Os relatórios dos professores/as guarani e kaiowá das terras indígenas já mencionadas, são fortes relatos que falam através de palavras registradas em papel e arquivadas por certo período e que corriam o risco de cair em abandono, mas que ganham nova vida. Ao ler Marilena Chauí em Experiência do Pensamento (2012), percebemos o quanto as linguagens desses relatórios se comunicam umas com a outras e transpóem barreiras geográficas entre nós, os escritos e os interlocutores. Sobre isso, Chauí (2012) escreve que

O mistério da linguagem está em que só exprime quando se faz esquecer e só se deixa esquecer quando consegue exprimir. Quando sou cativada por um livro não vejo letras sobre a página, náo olho sinais, mas participo de uma aventura que é pura significação e, no entanto, ela não poderia oferecer-se a mim senão como linguagem. [...] $\mathrm{O}$ triunfo da linguagem é o de nos fazer crer, que ao término de um livro, que nos comunicamos com o autor de espírito a espírito, sem palavras. (CHAUÍ, 2012, p.187/188)

Ainda sobre os relatórios dos professores/as guarani e kaiowá, compreendemos que as palavras que compóem seus textos estão marcadas por histórias, identidades, experiências profissionais e de vida, e muitas dessas palavras estão vivas em sentidos e significados. Utilizando-nos dos escritos de Pereira (2013, p. 213-214), 
poderíamos apresentar que os escritos presentes nos relatórios são "uma arena política, uma arma e um efeito da negociação".

O contato com os documentos da Ação Saberes Indígenas na Escola/MEC/ SECADI (ASIE), bem como com as dissertaçóes e textos de autoria guarani e kaiowá que também se fazem presentes no desenvolvimento do artigo, se encontram dentro de uma perspectiva de pesquisa documental e bibliográfica, mas nem por isso nos levam para longe dos nossos sujeitos de pesquisa, pelo contrário, nos aproximam ainda mais deles.

As leituras dos 14 relatórios selecionados foram realizadas em diversas ocasióes. Um mesmo relatório foi lido várias vezes, pois, relendo e revisitando os textos em diferentes dias, foi possível encontrar detalhes não percebidos em uma primeira leitura, bem como ter outro entendimento. Os escritos dos professores, voltados à pedagogia guarani e à sua prática pedagógica, foram sempre foco de atenção nos relatórios. Em alguns relatórios, esses assuntos eram destacados para uma leitura mais atenta. Procuramos realizar as leituras como se estivéssemos em uma roda de conversa, um diálogo constante com os professores que se faziam presentes através de seus escritos nos relatórios. Isso foi possível porque nos inspiramos em Paraíso (2014) e compreendemos que

[...] necessitamos ser abertas e flexíveis; não podemos ser rígidas em nenhum instante desse pesquisar, porque precisamos estar sempre abertas a modificar, (re)fazer, (re)organizar, (re)ver, (re)escrever tudo aquilo que vamos significando ao longo da nossa investigação. A inquietação constante, a experimentação, os (re)arranjos, o refazer, o retomar inúmeras vezes é parte do nosso modo de fazer pesquisa. (PARAÍSO, 2014, p. 43)

Foi necessário realizar diferentes formas de leituras dos relatórios, em alguns momentos de forma intensa, e em outros pausadamente, para que houvesse um momento de descanso nas percepçóes viciadas a partir de um único olhar, para que nossa visão não fosse traída pelo cansaço ou mesmo por percepçóes atravessadas. Esse cuidado não foi programado e se deu de forma silenciosa, como se os autores solicitassem, a nós, um descanso, um repouso, para no retorno poderem nos mostrar novos pontos e novos argumentos possíveis em nossa jornada de longos diálogos.

Esse exercício de pausa, repouso que se fez necessário, apenas foi reforçando que, ao retornar às leituras, a sala estava repleta de professores guarani e kaiowá, como se os/as intelectuais estivessem em roda, esperando pacientemente por nosso volta e generosamente retomassem o diálogo conosco, sanando dúvidas e trazendo respostas aos questionamentos. 


\section{O povo guarani e kaiowá no Mato Grosso do Sul: aspectos gerais}

O Mato Grosso do Sul, foco desse texto, possui o segundo maior contingente populacional indígena do Brasil. Com aproximadamente 80 mil índios (SESAIMS/2020), o estado compreende oito etnias indígenas, sendo o povo guarani e kaiowá a maior população presente no território sul mato-grossense. Dividido em pequenos grupos no Brasil e em outros países da América Latina, a população guarani é representada por três parcialidades culturais: nãndeva, mbya e kaiowá.

A história dos guarani e dos kaiowá no território sul mato-grossense é atravessada por várias e diferentes interferências não indígenas. Chamar de interferências parece-nos até mesmo amenizar a invasão desse território com o qual a população guarani e kaiowá tem uma relação que vai além de uma ocupação de espaço geográfico. Machado (2016, p. 45), em seu estudo, nos ajuda a compreender que "a base cultural tradicional e espiritual para esses povos é o tekoha, o ñande reko, ou seja, a terra, que para o povo indígena é essencial, sem ela nada acontece, é como se esses povos não existissem sem a terra, a natureza e o meio em que vivem".

Essa terra sagrada e repleta de espiritualidade tem sua história atravessada diretamente a partir de 1767, com a criação do Forte Iguatemi pelo governo português, que seria considerado o passo inicial para a ocupação do atual Mato Grosso do Sul (BRAND, 1997). Muitos/as autores/as guarani e kaiowá apontam essas ocupaçóes a partir da perspectiva de Antônio Brand, que ressalta:

[...] As primeiras frentes não-indígenas adentraram pelo território Kaiowá e Guarani, a partir da década de 1880, após a guerra do Paraguai quando se instala na regiáo a Companhia Matte Larangeira. Esta Companhia, embora não questionasse a posse da terra ocupada pelos índios, nem fixasse colonos e desalojasse comunidades, definitivamente, das suas terras, foi, contudo, responsável pelo deslocamento de inúmeras famílias e núcleos populacionais, tendo em vista a colheita em novos e por vezes distantes ervais. (BRAND, 2004, p. 139)

Esse povo passou por um violento processo de expulsão de suas terras, de modo que foram obrigados a se reorganizar social e culturalmente, pois, como já mencionado, o território faz parte de sua formação cultural e social. Dentro dessa complexa história, diferentes aspectos de interferência não indígena se fizeram presentes nas terras guarani, tais como: a Companhia Matte Larangeiras - 1882/1892; a criação do Serviço de Proteção ao Índio - 1910/1918 (Serviço de Proteção ao Índio); a criação da Colônia Agrícola Nacional de Dourados 
(CAND) - 1941/1943; a formação das Fazendas - 1958; e o início da indústria de exploração da cana-de-açúcar através das Usinas de Álcool - 1980.

Todas essas interferências foram responsáveis pelos movimentos de confinamento ${ }^{5}$ (BRAND, 1997) das populaçôes guarani e kaiowá, bem como pelo esparramo ${ }^{6}$ - para usar os mesmos termos que Brand (1993) e seus interlocutores na definição dos períodos de criação das reservas indígenas bem como pelo afastamento dessas populaçóes de seus territórios tradicionais. Segundo Aquino (2012),

[...] O objetivo do governo era criar as reservas e juntar os índios que viviam espalhados em vários lugares e arredores da mesma região para liberar as terras aos fazendeiros e praticar agricultura e criar gado. Por esse motivo os índios foram levados para área reservada. Muitos índios não queriam ir para esse local e insistiam em permanecer trabalhando nas redondezas porque os índios consideravam e respeitavam seus territórios tradicionais por entender que os espíritos dos antepassados protegiam o seu Tekoha (território). Sabese que até aquela época antes do esparramo dos parentes não havia fronteiras nem limites. Nas primeiras décadas do século vinte poucas famílias Guarani e Kaiowá viviam no espaço reservado, que apresentava áreas de terra próprias para a agricultura, com solos férteis, matas produtivas com áreas de cerrado e campo. Todas elas eram utilizadas para as práticas produtivas dos Guarani/Kaiowá, segundo seus usos e costumes. (AQUINO, 2012, p. 26)

A situação descrita por Aquino (2012) continua presente, pois o confinamento e o aumento da população guarani no interior das reservas indígenas demarcadas colaboraram para uma redução do espaço disponível de plantio, o que acarretou em um esgotamento dos recursos naturais e trouxe uma dificuldade quanto à produção de alimentos. Em virtude desses acontecimentos, muitos indígenas guarani passaram a depender de políticas de assistência social e de segurança alimentar presentes nas comunidades do Mato Grosso do Sul (BRAND, 1997; 2004).

5 Segundo Brand, o confinamento dos kaiowá e guarani deu-se por diferentes fatores, em especial, em decorrência da perda de seus territórios tradicionais, provocando a falta de condiçôes para manterem seu modo de ser nos tekoha (aldeias) tradicionais, fazendo com que se aglutinassem dentro das reservas instaladas pelo SPI.

6 O termo esparramo, segundo Brand, foi amplamente empregado pelos informantes indígenas para caracterizar o processo de destruição das aldeias e o desmantelamento das famílias extensas em função do desmatamento. É o processo de dispersão que precede o confinamento no interior das reservas. 


\section{A pedagogia guarani na percepção dos professores guarani e kaiowá}

A questão pedagógica é um tema muito abordado no meio acadêmico, e podemos encontrar diferentes definiçóes, conceitos e percepçóes de pedagogia. Para os professores guarani e kaiowá, muitas são as estratégias, discussóes e reflexôes acerca dessa temática, principalmente dentro da reflexão de como se dá esse processo. Para melhor compreender esse contexto, recorremos aos escritos de Benites (2014), precisamente quando aponta que

[...] Mesmo com o grande esforço dos professores indígenas de fazer o "diferente" na sua prática pedagógica, eles ainda se movem dentro do sistema tradicional de educação colonizador e homogeneizador, a partir do qual foi construída a sua identidade. Para romper essas algemas procuramos, nos espaços alternativos do contexto escolar, fazer a educação com a metodologia Guarani e Kaiowá. Mas parece que a necessidade de responder às demandas externas - e não às internas - ainda orienta a prática da educação escolar. (BENITES, 2014, p. 127)

Seguindo o pensamento do autor, entendemos o quanto a sala de aula pode engessar práticas que saem da lógica do convencional, que negam outros tempos, espaços, saberes e conhecimentos (ARROYO, 2012). Ainda nessa direção, tivemos a oportunidade de perceber o quanto esse ambiente é propicio ao corte de laços construídos ao longo do tempo, com aquilo que nós educadores entendemos ser uma prática pedagógica, que se desvencilham das teorias que anulam e negam a existência de pedagogias outras. Nesse sentido, uma frase, nos tocou e afetou durante a leitura; no rodapé de uma página do relatório R14 dizia: "não colonizamos nossos alunos, não precisamos de colonizadores” (R14, Taquapery, Coronel Sapucaia/MS, 2018).

A partir da experiência com o povo guarani, assim como em outros contextos indígenas, podemos pensar que a escola indígena, ou seja, o espaço de sala de aula, não é único lugar de aprendizagem. Para os povos indígenas o ensinoaprendizagem acontece nas diferentes formas e nos mais diversos lugares. De acordo com Scaramuzza e Nascimento (2018), essa separação do entendimento de escola e aprendizagem é uma pista para compreender a interculturalidade. Sobre esse conceito, os autores entendem que

[...] A interculturalidade, possivelmente, pode referir-se a uma abertura que permite a construção de estratégias 
capazes de identificar, perceber, conviver e trocar experiências com sujeitos e matrizes culturais distintas na construção de um mundo melhor. Conforme aprendemos com os professores indígenas, a interculturalidade refere-se a uma estratégia que ultrapassa a crítica ao capital. Centrase na dimensão da cultura na medida em que requer do próprio sujeito em situação intercultural conhecer os códigos referenciais de sua cultura e estar disposto a "ganhar" e "perder" qualitativamente seus significados com a diferença (NASCIMENTO e SCARAMUZZA, 2018, p. 563).

Dentro da lógica inferiorizante e colonizadora da teoria pedagógica moderna, relacionarmo-nos com os interlocutores da pesquisa e com os relatórios por eles produzidos foi um momento que nos permitiu um espaço para respirar, ainda não aliviados, mas com esperança de que temos muito a aprender a partir da pedagogia guarani.

A compreensão de que existem pedagogias diferentes e a forma respeitosa como são tratadas e apontadas em alguns relatórios que abordam o tema chama a atenção. É importante ressaltar que nem todos os relatórios vão trazer comparaçóes, mas os que o fazem seguem a mesma forma de abordagem, indicando a compreensão de que se trata de diferentes sistemas com configuraçóes próprias à sua cultura, ao mesmo tempo em que realizam críticas profundas às teorias inferiorizantes, hierárquicas, dominantes e colonizadoras da pedagógica moderna. Esse processo acaba ocorrendo, porque, segundo Lander (2005), o pensamento científico moderno colaborou para a naturalização das características das sociedades ocidentais modernas, como expressóes do desenvolvimento histórico da humanidade e, mesmo depois do fim do período colonial, permaneceram favorecendo aspectos da cultura europeia.

Em outras palavras, observamos o quanto a colonialidade se faz presente, transitando nos mais diferentes espaços, influenciando e posicionando a nossa forma de "ver" e compreender o outro, marcando nossas representaçóes e criando um padrão de controle (QUIJANO, 2005). Isso evidencia que a colonialidade não se esgotou com o colonialismo, pois sua presença interfere na produção da identidade e da diferença dos povos indígenas, assim como colabora para que os nossos discursos e posicionamentos apresentem o sujeito que está na fronteira da exclusão como uma pessoa desproporcional, em oposição, em condição de subalternização ou em dominação.

Ainda, sobre o assunto, Benites (2014) escreve que suas pedagogias próprias é que possibilitarão as mudanças necessárias para a comunidade indígena. 
A prática pedagógica deve contribuir para que o sujeito construa o caminho, utilizando as experiências, os diversos olhares, buscando a integração e a diversidade. $\mathrm{O}$ que buscamos é a retomada a uma posição onde a natureza é uma rede de interligação física, espiritual, social, ambiental, e o papel do homem neste contexto é atuar para fortalecer esta rede a partir da consciência crítica e reflexiva. (BENITES, 2014, p. 128)

Em sua grande maioria, os relatórios da Ação Saberes Indígenas na Escola/ MEC/SECADI (ASIE) se preocupam em detalhar a pedagogia guarani da forma mais específica possível, relatando suas práticas e descrevendo o espaço por ela ocupada dentro do dia a dia da aldeia. A pedagogia guarani independe do espaço físico da escola, das paredes e da sala de aula: não existe uma formação acadêmica responsável por formar e transmitir, pois o conhecimento e os saberes nela contidos vêm através da oralidade e do conviver em comunidade, sem uma hierarquização imposta que elege um detentor desse conhecimento (ABREU, 2020). Nesse sentido, alguns relatórios assinalam essa compreensão, como podemos verificar no seguinte trecho:

As pedagogias indígenas é uma técnica que não tem hora e tempo. Pois cada coisa se faz conforme a necessidade, porém pedagogia convencional tem suas configuração e moldes. Contudo, Guarani é diferente deles, haja visto que se trata de um sistema de um povo cada qual tem suas normas e configurações próprias. (R3, Guaimbé, Laguna Caarapá/MS, 2018)

Ainda sobre o assunto, outro relatório contribui para novas inquietaçóes:

A pedagogia Guarani é tudo que os pais ensinam as crianças desde pequeno, de como viver bem, falar na língua, suas danças, rezas, contos e muito mais. É também os Guarani já ensinam como resistir na luta contra o preconceito de todo os lados. A pedagogia não tem nada a ver com livros, cadernos e lápis, mas com conhecimento que já vem a muito tempo com seus povos, suas culturas. Até hoje essa pedagogia vive ainda dentro da escola, na sala e no meio da comunidade. (R12, Taquapery, Coronel Sapucaia/MS, 2018)

As realizaçóes desses processos pedagógicos fazem parte do dia a dia, estão nas origens da comunidade, no viver dos acontecimentos e nas práticas realizadas, 
mas não como algo automático, nem como algo programado mecanicamente. Existe a consciência de que os saberes tradicionais devam ser transmitidos e os conhecimentos compartilhados. Realizando uma escuta sensível desses relatórios e conhecendo a cultura guarani, é possível mencionar que existe um movimento, uma vontade e uma necessidade de fazer acontecer essa pedagogia.

Nos padróes ocidentais, dentro da lógica colonizadora, a pedagogia é uma ciência que se transmite através de livros, dentro das salas de aula das universidades e que apenas um número restrito de pessoas possui. Nas escolas, ela será apenas aplicada, e não compartilhada entre educadores e educandos, sempre com o olhar de que existe aquele que possui o conhecimento e aqueles que precisam ser dominados. Entendemos que existem educadores que quebram esses paradigmas, assim como teorias que se chocam com essa perspectiva, porém esses ainda são minoria dentro de um sistema hierárquico e homogeneizador.

A pedagogia guarani quebra essa hierarquização, pois os mais velhos, chamados de anciãos, não são os únicos responsáveis por compartilhar os conhecimentos tradicionais. Pela lógica, é compreensível que eles sejam os principais responsáveis por compartilhar os modos e práticas tradicionais, porém, no caso da pedagogia guarani, o coletivo como um todo tem sua parcela de contribuiçáo, e até mesmo as crianças têm um papel fundamental nessa troca, pois apresentam um lugar social e estratégico na comunidade. A partir dos seguintes relatórios, verificamos essa situação:

A Pedagogia Guarani é aquela que está no conhecimento e reconhecimento de cada povo, está direcionado ao saberes, construído e reconstruído de valores importante para o povo, assim como educaçáo, ensinamento os valores materiais e imateriais. Conhecimento pelo qual o povo Guarani se auto identifica como povo diferente. A língua Guarani, o canto a reza o mito e entendimento de mundo e sua manifestaçáo no povo. (R8, Taquapery, Coronel Sapucaia/MS, 2018)

Falar de pedagogia do guarani kaiowa, lembra muito a fala do nosso "nhamoi", avo, que é gostoso estar unido e coletivo, a educação recebemos ao redor do fogo. A pedagogia kaiowa se inicia para ser coletivo e unido, em segundo lugar lembram o nosso espaço e tempo educativo; exemplo as crianças tem que aprender ouvir o canto do pássaro ao amanhecer, saber identificar os astros e obedecer todo orientação dos rezadores e lugar dos quais participam as pessoas, as famílias. A comunidade e todo o membro da família. Desde modo a educação assumida como responsabilidade coletiva. (R9, Taquapery, Coronel Sapucaia/MS, 2018) 
Os conhecimentos se dão em comunidade e todos podem contribuir: cada um exerce um papel no desenvolvimento da pedagogia guarani, e a participaçáo de todos os membros da comunidade e da família fica visível. O respeito aos membros da comunidade é uma prática contida na pedagogia guarani, e não são apenas os pais que se encarregam de compartilhar esse conhecimento: avôs, avós, tios e tias, irmãos e irmãs, professores/as, lideranças e anciãos, todos fazem parte desse processo de desenvolvimento das crianças.

A partilha desses conhecimentos vai ocorrendo nas atividades rotineiras, como uma caminhada até algum ponto da aldeia. Nesses momentos, aquele que acompanha a criança aproveitará essa atividade para lhe transmitir os conhecimentos básicos, como a melhor forma de percorrer o caminho para chegar ao local desejado. As plantas ou animais avistados ao longo da caminhada darão o tom da conversa e dos ensinamentos, o saber ouvir fará parte desses aprendizados e, dessa forma, muito é compartilhado. Dialogando com Walsh (2016, p. 67), podemos perceber que a pedagogia guarani está para o "construir possibilidade de relacionamento em vez de individualidade e competência. Esse é um espaço e lugar para dialogar, pensar, analisar, teorizar e fazê-lo em comunidade e em comum, que motiva alianças, compromissos, colaboraçóes e interculturalizaçóes [...]".

Para os guarani, aprender não está relacionado ao conteúdo específico ensinado em sala de aula, está além, é anterior, posterior e permanente no processo educacional, fora e dentro de sala de aula. É uma educaçáo para a vida (AQUINO, 2012). Sobre essa discussão, Bergamaschi aponta que

Predomina, entre os Guarani, duas formas de aprender. Uma, está ligada ao esforço pessoal, é a busca, desencadeada pela curiosidade que se desenvolve na pessoa, desde pequena. A outra, é revelaçáo e se relaciona com à primeira, pois para receber a revelaçáo das divindades a pessoa também faz um esforço para viver de acordo com o Nhande Reko. Conhecimento para os Guarani é expressado através da palavra Arandu: Ara significa tempo, dia; Nendu quer dizer sentir, experimentar. Nessa perspectiva, Arandu significa sentir o tempo, fazer o tempo agir na pessoa. As duas formas de aprender acima mencionadas estáo ligadas ao tempo [...] (BERGAMASCHI, 2005, p. 154/155).

Nessa mesma direção, o relatório R9 destaca que

[...] A orientação da pedagogia Kaiowá saber ouvir as palavras "nhe'e" a base de aprendizagem é na família e alcançar a velhice, na família que se aprende a viver bem; ser bom caçador, um bom pescador, um bom marido, 
uma boa esposa, um bom filho, um membro solidário e hospitaleiro da comunidade. Aprende se a fazer roça, plantar, fazer artesanato, aprende se a cuidar da saúde, benzer, curar doença, conhecer plantas medicinais, aprende se ser respeitoso da natureza e das pessoas, não existem de avaliação e reprovação mas tem que aprender, tudo isso é pedagogia. Serviço e ao alcance de todos; aprender-se a viver e combater qualquer mal social. Portanto entendo isso como pedagogia indígena por que nessa linha que nos indígenas aprende a viver no mundo. Pedagogia indígena está relacionado ouvir e praticar, amar, e ter fé tudo aquilo que aprende. (R9, Taquapery, Coronel Sapucaia/MS, 2018)

A troca faz parte desse processo, e as crianças são tratadas com respeito e como seres que estão em formação que também possuem algo para contribuir. Não existe um marco para iniciar. É perceptível que esse processo pedagógico perpassa mais do que apenas ensinar e aprender.

Nesse contexto, a pedagogia guarani possui uma lógica própria, que faz parte de sua formação cultural, do dia a dia e do convívio. Esse processo pedagógico não precisou estar registrado em livros, como uma cartilha ocidental que leva o passo a passo para se aplicar diferentes práticas pedagógicas. Foi e é através da oralidade que a pedagogia guarani se faz presente nas casas, nas escolas e em todos os espaços da aldeia:

A educação à vida vai acontecendo no dia a dia e em vários locais: seja na beira do fogo, da madrugada, no amanhecer, quando os conselhos de nossos avós tinham mais sucesso, porque nosso deus usava a boca deles para repreender os espíritos da desobediência. A educação nunca acontecia na ponta do lápis ou no papel; os indígenas não conheciam os desenhos esquisitos que chamamos de letras, que atrapalham o desenvolvimento do conhecimento tradicional. (AQUINO, 2012, p. 49).

Mesmo com toda a interferência não indígena ao longo da história dos guarani e dos kaiowá, a prática de sua pedagogia náo foi deixada de lado. As mudanças que foram impostas forçadamente na cultura desses povos não conseguiram excluir a prática da pedagogia guarani.

A língua materna, que foi alvo dos não indígenas a partir do processo de colonização, é uma forma de resistência e faz parte dessa pedagogia. Apesar de ser vista como silenciosa e algumas vezes invisível, notamos que a pedagogia guarani, além de uma forte presença afirmativa, é incômoda, desestabiliza, provoca 
e constrói açôes coletivas que ressignificam e desconstroem modelos "ditos" canônicos (ARROYO, 2012).

Voltando a discussão ao modelo pedagógico guarani e sua relação com a língua, observamos na escrita do relatório R13 que

[...] a pedagogia guarani esta muito ligado a cultura e a língua materna são esses alicerces que o guarani carrega desde a infância no caso a cultura no conhecimento guarani nos fomos batizados pelo Tupã deus junto com a natureza para vivermos aqui na terra a pedagogia acontece em três momentos importantes perto do fogo a criança recebe todos os conhecimentos que a mãe recebe do pai e dos seus avos que a pedagogia de ouvir (R13, Rancho Jacaré, Laguna Caarapã/MS, 2018).

O fogo é um elemento de destaque não somente nos vários relatórios, mas também nas dissertaçóes e textos que narram a cultura guarani e kaiowá; sua importância aparenta estar acima do poder de aquecer e iluminar. Assim como o fogo faz parte desse processo de aprendizagem, também está presente nas concepçóes de espiritualidade e da cosmovisão guarani.

Os elementos da natureza e da vivência em comunidade como um todo estão presentes no aprendizado. Percebemos que é através deles que a criança vai aprender não somente os fatores importantes de sobrevivência, mas também os valores que esses elementos possuem na construção de seu ser social diante da comunidade.

Ainda nesse mesmo relatório, os seus escritos destacam que

[...] A pedagogia guarani perto do fogo a criança aprende os nomes de todos os pássaros os cantos e a sua importância o valor da pintura guarani a importância da língua materna os comportamentos cultural guarani a importância do mito da lua e do sol onde e o espaço da criança e onde não é, aprende a história do seu pai e da sua mãe e pedagogia da oralidade assim a criança se sente seguro e se sente seguro com a sua vida e pronto para ir receber uma outra regra.(R13, Rancho Jacaré, Laguna Caarapã/MS, 2018)

A pedagogia guarani transcende o escolar. A importância do papel de cada membro da comunidade é apontada de diferentes formas, e muitas vezes, o mesmo membro pode exercer diferentes papéis. Esses papéis não são necessariamente fixos, eles podem se adequar conforme o momento ou a necessidade do coletivo 
naquele instante. $\mathrm{O}$ aprendizado das crianças, o compartilhar dos conhecimentos se dão em atividades rotineiras e também em atividades específicas, que têm horários e locais específicos para acontecer.

Não é fácil compreender os processos dessa aprendizagem, colocandoos como algo que está presente no dia a dia, desde os pequenos aos grandes acontecimentos. Eles podem nos levar a cair na falsa ilusão de que essa pedagogia é simples e facilmente pode ser entendida por quem a analisa de forma superficial, mas nos próprios relatórios encontramos pontos que contrapóem essa percepção. Segundo o relatório R4,

[...] A pedagogia guarani é complexa, ela é o pilar da cosmovisão que procede em toda a vida do indivíduo guarani que começa a partir do nascimento de uma criança. São todas as formas de ensinamento segundo os preceitos da cultura. É preciso entender que a pedagogia, o modo de ser, toda a expressão ética vivida pelo guarani está ligado diretamente ao mundo da espiritualidade, ou seja, a imitação do modo de ser deixado pelos ancestrais Pai Kuara e Pai Vangaju, que uma vez foram deixado suas funçôes profética pelo seu Pai. Isso não é delimitado no espaço e tempo, e nem linear, como do conhecimento ocidental. O conhecimento guarani dessa maneira corre por outro caminho e por outra lógica. (R4, Taquapery, Coronel Sapucaia/MS, 2018)

Toda essa complexidade está em cada detalhe e, ao mesmo tempo, na simplicidade de cada ação. Assim como cada membro possui um papel na formação dos mais novos, os papéis são múltiplos, bem como os papéis das crianças são modificados e ressignificados conforme a necessidade coletiva. As crianças exercem um papel essencial no contexto social. A ausência da linearidade pode ser um problema para nós não indígenas, mas para os guarani e para os kaiowá é nessa ausência que as aprendizagens se dão, de forma não imposta, de modo que se respeite o espaço e tempo de crescer de cada criança, ao mesmo tempo em que se guiará esses processos.

Assim, o relatório R4 continua afirmando que

[...] Outro ponto muito importante que, diante do vasto conhecimento guarani, deve ser levado em consideraçáo é o Arandu, uma forma de pedagogia específica para o fortalecimento e entendimento da sua cosmovisão. Cada indivíduo nesse contexto passa por um processo longo e contínuo de formação diferenciado e toda sua expressão 
ética é espelhada nos ancestrais, na expectativa de ter o Teko Porã, um bom modo de ser - Tavyterã ou Guarani Kaiowa. Diante dessa lógica, afirmamos que o Arandu é muito importante para o Tavyterã, seja no ensino seja na aprendizagem, mas ocorre um confronto com as várias imposiçóes dos não indígenas que oprimem em vários aspectos e das mais variadas formas a cultura milenar desses povos. (R4, Taquapery, Coronel Sapucaia/MS, 2018)

As imposiçóes dos não indígenas ao longo dos anos tentou modificar esse jeito de ser guarani e kaiowá, pretendendo mudar sua pedagogia, colocando em avaliação e julgamento essas práticas pedagógicas. Para muitos, esses modelos próprios de ensinar, alicerçados na oralidade, na tradição, na vida e na espiritualidade não são compreensíveis, assim como muitos não fazem esforço para entender essa prática pedagógica. Isso é resultado da formação moderna/ colonial que continua a entender que o válido, o legítimo e o reconhecido é aquele escrito em livros, que é considerado corrente teórica e que faz parte de um processo de dominação.

Em muitos dos relatórios analisados é possível identificar que os professores guarani e kaiowá compreendem a Ação Saberes Indígena na Escola como uma proposta de interculturalidade que se materializa como uma ferramenta pedagógica presente na escola. De acordo com Walsh (2009), essa ferramenta

questiona continuamente a racialização, subalternização, inferiorização e seus padróes de poder, visibiliza maneiras diferentes de ser, viver e saber e busca o desenvolvimento e criação de compreensôes e condiçôes que não só articulam e fazem dialogar as diferenças num marco de legitimidade, dignidade, igualdade, equidade e respeito [...]. (WALSH, 2009, p. 25)

Concordamos com a autora, pois observamos que, para os professores guarani e kaiowá, a interculturalidade auxilia a escola indígena a trabalhar e caminhar numa perspectiva dialógica plural, em que é exigido dos docentes um compromisso ético e um espaço aberto para negociaçóes, desconstruçóes, mudanças e um fortalecimento dos seus saberes, de seus conhecimentos e da pedagogia guarani. 


\section{Palavras finais}

O texto, além de apresentar a percepção dos professores guarani e kaiowá de Mato Grosso do Sul sobre a pedagogia guarani a partir dos relatórios da Açáo Saberes Indígena na Escola/MEC/SECADI, nos faz perceber o quanto somos fruto dessa lógica opressora, homogeneizante, colonizadora, que aceita e valida teorias dominantes. Conforme avançávamos na leitura e nos envolvíamos nas análises dos relatórios, sempre mantendo uma certa vigilância epistemológica e respeito, muitas desconstruçóes ocorreriam, principalmente na maneira como pensamos nossas pedagogias e enxergamos o outro nesse processo de ensino e aprendizagem.

Os estudos mostraram que a pedagogia guarani faz parte do viver, do conviver, do ouvir, do transmitir, do falar, do rezar, do pedir, do atender e do compartilhar de cada membro da comunidade, desde seu nascimento. As crianças vão sendo guiadas à vida adulta compreendendo a sua importância para o coletivo e compreendendo a importância do coletivo para cada indivíduo: quando os papéis são compreendidos, a coletividade funcionará a favor de todos.

Os relatórios analisados ressaltaram que existem diferentes olhares - nem sempre os/as professores/as vão concordar em todos os aspectos educacionais e escolares, mas as percepçóes e entendimentos em torno da pedagogia guarani dialogam e ressoam entre si, possibilitando que essa pedagogia esteja presente dentro e fora do espaço da escola indígena.

A Ação Saberes Indígena na Escola/MEC/SECADI, presente nas terras indígenas estudadas, trouxe uma participação efetiva da comunidade na escola, pois ela possibilitou a abertura e o respeito sobre os valores da educação guarani para o ensino tradicional e curricular, fazendo com os que os pais acompanhem mais seus filhos nas instituições de ensino. Para muitos professores guarani e kaiowá das terras indígenas onde os relatórios foram analisados, a Ação Saberes Indígena na Escola pode ser considerada um projeto de interculturalidade em que "processos e lutas que se entrecruzaram conceitualmente e pedagogicamente, [...] fazem questionar, transformar, sacudir, rearticular e construir" (WALSH, 2009, p. 25).

Todo esse contexto, ou seja, essa lógica, é levado para a sala de aula, para os espaços das escolas, compartilhada nos diferentes espaços possíveis de serem considerados educacionais. Quando decidimos interagir com os relatórios, tomar um posicionamento frente a cada registro, partilhar com quem os lê através dos nossos posicionamentos e da nossa percepçáo, notamos que essa lógica perpassa os espaços das aldeias guarani e kaiowá. Em outras palavras, podemos afirmar que ela entra no espaço acadêmico já ocupado por intelectuais, mas com outra perspectiva: 
a perspectiva do olhar não indígena, que busca compreender, assimilar, respeitar e compartilhar, através dos nossos afetamentos, os conhecimentos proporcionados durante essa interação entre nós, pesquisadores não indígenas, e os guarani e kaiowá de Mato Grosso do Sul.

\section{REFERÊNCIAS}

ABREU, A. J. de. A pedagogia guarani nas percepçóes dos professores guarani e kaiowá: um estudo a partir dos relatórios da Ação Saberes Indígenas na Escola. Dissertaçáo de Mestrado. Programa de Pós-Graduação em Educação, Universidade Católica Dom Bosco, Campo Grande, 2019.

ARROYO, M. G. Outros sujeitos, outras pedagogias. Petrópolis/RJ: Ed. Vozes, 2014.

BENITES, E. Oguata Pyahu (Uma Nova Caminhada) no Processo de Desconstruçáo e Construçáo da Educação Escolar Indígena da Aldeia Te'ýikue. Dissertação de Mestrado. Programa de Pós-Graduação em Educação, Universidade Católica Dom Bosco, Campo Grande, 2014.

BERGAMASCHI, M. A. Nhembo'e ¡enquanto o encanto permanece! Processos e práticas de escolarizaçáo nas aldeias Guarani. Tese de Doutorado. Programa de Pós-Graduação em Educação, Universidade Federal do Rio Grande do Sul, Porto Alegre, 2005.

BRAND, A. J. O confinamento e seu impacto sobre os Pãi/Kaiowá. Dissertação de Mestrado. Programa de Pós-Graduação em História, Pontifícia Universidade Católica do Rio Grande do Sul, Porto Alegre, 1993.

. O impacto da perda da terra sobre a tradiçáo kaiowál guarani: os difíceis caminhos da Palavra. Tese de Doutorado. Programa de PósGraduação em História, Pontifícia Universidade Católica do Rio Grande do Sul, Porto Alegre, 1997.

. Os complexos caminhos da luta pela terra entre os Kaiowá e Guarani no MS. Revista Tellus, Campo Grande, ano 4, n. 6, p. 137-150, abr. 2004.

BRASIL. Ministério da Educação. Portaria no 1.061 de 30 de outubro de 2013. Institui a Ação Saberes Indígenas na Escola. Brasília, DF, 2013.

CHAUÍ, M. Experiência do pensamento: ensaios sobre a obra de MerleauPonty. São Paulo: Martins Fontes, 2002. 
LANDER, E. Ciências sociais: saberes coloniais e eurocêntricos. In: LANDER, E. A colonialidade do saber, eurocentrismo e ciências sociais: perspectivas latino-americanas. Buenos Aires: Clacso, 2005.

LESCANO, C. P. Tavyterã Reko Rokyta: os pilares da educação Guarani Kaiowá nos processos próprios de ensino e aprendizagem. Dissertação de Mestrado. Programa de Pós-Graduação em Educação, Universidade Católica Dom Bosco, Campo Grande, 2016.

MACHADO, M. A. Educaçáo infantil: criança Guarani e Kaiowá da Reserva Indígena de Dourados. Dissertação de Mestrado. Programa de Pós-Graduação em Educação, Universidade Federal da Grande Dourados, Dourados, 2016.

PARAÍSO, M. A. Metodologias de pesquisas pós-críticas em educação e currículo: trajetórias, pressupostos, procedimentos e estratégias analíticas. In: MEYER, D. E.; PARAISO, M. A. (orgs.). Metodologias de pesquisa pós-crítica em educação. Belo Horizonte: Mazza Ediçóes, 2012. p. 15-30.

PEREIRA, M. V. A escrita acadêmica - do excessivo ao razoável. Revista Brasileira de Educaçáo, Rio de Janeiro, v. 18, n. 52, p. 213-244, jan.-mar. 2013.

QUIJANO, A. Colonialidade do poder, eurocentrismo e América Latina. In: LANDER, E. (org.). A colonialidade do saber: eurocentrismo e ciências sociais: perspectivas latino-americanas. Buenos Aires: Clacso, set. 2005. p. 107-130. (Colección Sur).

SCARAMUZZA, G. F; NASCIMENTO, A. C. Produzir a Educação Intercultural na Escola Indígena: desafios aos educadores de um novo tempo. In: Currículo sem Fronteiras, Porto Alegre, v. 18, p. 550-565, 2018.

WALSH, C. Interculturalidade, crítica e pedagogia decolonial: in-surgir, reexistir e re-viver. In: CANDAU, V. M. (Org.). Educaçáo intercultural na América Latina: entre concepçóes, tensóes e propostas. Rio de Janeiro: 7 Letras, 2009. p. $12-43$.

- Notas pedagógicas a partir das brechas decoloniais. In: CANDAU, V. M. (Org.). Interculturalizar, descolonizar, democratizar: uma educação "outra”? Rio de Janeiro: 7 Letras, 2016. (p. 64 -75). 